\title{
Could soluble minerals be dangerous for human health? The epsomite case study
}

DR. MATTEO GIORDANI, PHD ${ }^{1}$, MICHELE MATTIOLI ${ }^{1}$, MARIA ASSUNTA MELI ${ }^{1}$, CARLA ROSELLI ${ }^{1}$, IVAN FAGIOLINO $^{2}$, LAURA VALENTINI ${ }^{1}$, FABIO PERUZZI $^{3}$ AND MICHELE BETTI ${ }^{1}$

${ }^{1}$ University of Urbino Carlo Bo

${ }^{2}$ Gruppo C.S.A. spa

${ }^{3}$ Speleological Federation of the Emilia-Romagna Region

Presenting Author: matteo.giordani@uniurb.it

Due to their potential hazardousness for humans, the attention of scientists to mineral fibers is very increased especially to very small fibers and fibrils of inhalable size (length $>5 \mu \mathrm{m}$, diameter $<3 \mu \mathrm{m}$, diameter-length ratio $>1: 3$ ). Among these, there are the asbestos minerals (chrysotile, amosite, crocidolite, tremolite, actinolite, anthophyllite), fibrous antigorite and balangeroite, the amphiboles winchite, richterite and fluoro-edenite, the zeolites erionite, offretite, ferrierite and mordenite, and also talc and clay minerals as sepiolite and palygorskite. Many factors play roles on their toxicity, but the most important are the size of the fibers (length, diameter, relative ratio and aerodynamic equivalent diameter) and their chemical composition.

However, the branch of particulate and fibers with high solubility in water and/or in biological environments has not been taken into account and the knowledge at date is very scarce. In such case features, processes and all the involved reactions are completely different with respect to bio-persistent fibrous minerals, but a lower or even negligible biopersistence does not exclude them from being potentially dangerous for humans in other ways. Moreover, it is widely known that any particle at sufficiently high lung burdens may cause lung damage, and then "biologically inert" particles do not exist. Lipophilicity, hydrophilicity and molecular size are the major determinants for the rate of solutes absorptive processes and water-soluble substances that reach the interstitium are cleared by diffusion into blood and lymph capillaries.

In this study, samples of natural epsomite fibers (soluble in water) from Perticara mine, Italy, were investigated, and SEMEDS, XRPD, EDPXRF data were combined and integrated to characterize morphology, crystal chemistry and mineralogy of epsomite. Through this study, we want to focus attention on soluble minerals fractions with the example of epsomite, which can be present both in the natural environment and buildings and that have never been taken into consideration from the point of view of their potential dangerousness. Our study represents a first step towards understanding a world that is still almost totally unknown but which could lead to significant results. 